\title{
Mechanical system detector of weight in motion system
}

\author{
Aleksander Nieoczym ${ }^{1, *}$, Kazimierz Drozd ${ }^{1}$, and Andrzej Wójcik ${ }^{1}$ \\ ${ }^{1}$ Lublin University of Technology, Faculty of Mechanical Engineering, Nadbystrzycka 36 street, 20-618 Lublin, Poland
}

\begin{abstract}
The multi-sensor and mechanical WIM systems were characterised. The assumption of the necessity of simultaneous analysis of vehicles types (by number of wheels, e.g. two-wheelers, four wheelers, etc.) participating in traffic, was made. This type of analysis involves not only the measurement of vehicle weight but also qualitative detection. Such data are mainly collected and analysed in urban traffic, in which information on traffic volume, lane occupancy or the number of vehicles waiting to enter an intersection are important to ensure continuous, smooth traffic flow. This article presents a design of a WIM system in which the detector is a beam with Bragg grating optical fibre sensors glued on it. Four cases of beam load were determined, due to its strength and the ability to register deformations. The strength analysis of the beam was carried out with the help of MES and its shape was optimised.
\end{abstract}

\section{Introduction}

Weigh-in-Motion (WIM) systems are designed for weighing vehicles driving across a measurement site. Because during measurements the vehicle has to come in physical contact with the components of the system, WIM systems always use built-in sensors installed in the road pavement.

The accuracy of WIM measurements is determined by the measuring conditions, including

- vehicle speed,

- quality of the road pavement in which the WIM system is installed [1],

- properties of the force sensors used [2, 3],

- calibration procedure and frequency of system calibration $[4,5,6,7,8]$,

- algorithm used for estimating static load and gross vehicle weight [9].

WIM systems are divided with respect to design and functionality criteria into two types: multi-sensor (MSWIM) and classic mechanical systems. MS-WIM is a multi-configuration system based on inductive loop systems with an optionally installed axle detector and polymer or quartz force sensors. The force sensors are distributed evenly along the measuring area. Each pair of force sensors is surrounded by an inductive loop, thus creating a dual-sensor WIM subsystem [10].

Mechanical WIM systems use piezoelectric and strain gauge sensors as vehicle-load-converting elements. Axle loads and vehicle weights can also be measured using detectors that have the form of a platform supported on mechanical elements (columns, beams), so-called "load cells", which are equipped with strain gauges for measuring deflexion of cells.

WIM measuring systems described above are used as dynamic in-motion scales designed to monitor the weight of vehicles with a maximum permissible gross weight in the range from $3500 \mathrm{~kg}$ to $36000 \mathrm{~kg}$. However, apart from weighing vehicles, it is often also necessary to simultaneously analyse what types of vehicles (by number of wheels, e.g. two-wheelers, four wheelers, etc.) are participating in traffic. This type of analysis involves not only the measurement of vehicle weight but also qualitative detection. Such data are mainly collected and analysed in urban traffic, in which information on traffic volume, lane occupancy or the number of vehicles waiting to enter an intersection are important from the point of view of ensuring continuous, smooth traffic flow. This article presents a design of a WIM system in which the detector is a beam with Bragg grating optical fibre sensors glued on it. Fibre Bragg Gratings (FBG) are wavelength shift sensors, in which the wavelength of light shifts under the influence of the parameter measured

\section{Design of the beam detector}

The system was designed to detect the presence and measure the weight of various vehicles ranging from motorcycles to lorries. It was assumed that in a twowheeled vehicle, the tyre force was $1000 \mathrm{~N}$. A single axle of a truck with a gross vehicle weight $\mathrm{m}=10000 \mathrm{~kg}$ exerts a force of $60000 \mathrm{~N}$. FBG sensors had a length of $15 \mathrm{~mm}$ and a diameter $\phi 2$. The maximum relative elongation must not exceed $\varepsilon_{\max }=0,003(0,3 \%)$, with the minimum value $\varepsilon_{\min }=0,000015(0,0015 \%)$. Max elongation of the sensor $\mathrm{u}=0,045 \mathrm{~mm}$.

Four cases of loading of the beam were considered which were important from the point of view of beam strength and the possibility of registering deformations (Table 1). Case $2 \mathrm{~b}$ is related to permissible beam stresses and the maximum elongation of the sensor. Case $1 \mathrm{a}$ is associated with the minimum beam deformations that a fibre optic sensor can register.

${ }^{*}$ Corresponding author: a.nieoczym $@$ pollub.pl 
Table 1. Cases of beam loading.

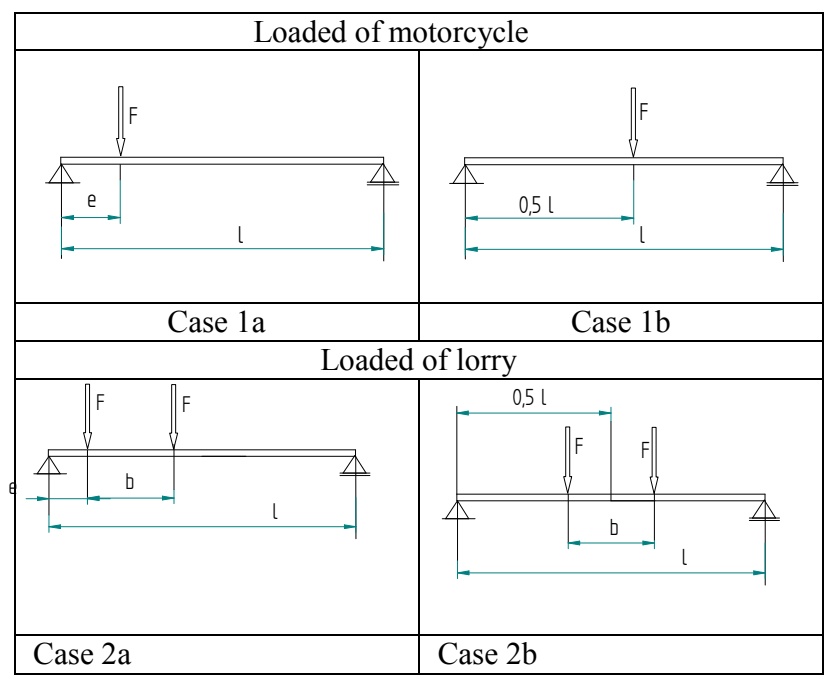

In cases in which a beam is loaded with the weight of a motorcycle, the placement of fibre optic sensors on the beam is important. They must be glued in regions of maximum beam deflexion. The crux of the problem, therefore, is to calculate the value of the bending moment generated in the beam under the influence of a singletrack vehicle and then to calculate whether the relative deformation of the beam under the influence of this moment can be registered by the fibre optic sensor. Deflexion of the beam, uniquely defined by maximum deflexion $f$, is associated with its deflexion line. Maximum deflexion indicates that fibre optic sensors should be placed symmetrically at a distance of $240 \mathrm{~mm}$ from the centre of the beam at points P1, P2 and P3 beam in Fig. 1.

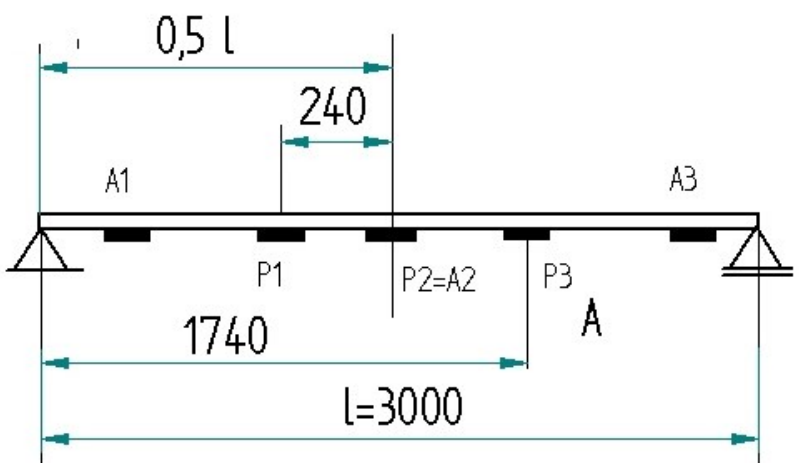

Fig. 1. Location of sensors: P1, P2, P3 - placement points for fibre optic sensors determined in beam deflexion calculations, A1, A2, A3 - sensor placement points resulting from geometric optimisation of the beam.

FEM strength calculations using Abaqus software were conducted. The results of modelling - points P1, P2, P3 are shown in Table 2 and Fig. $4-6$.

\section{Results}

- Maximum stress produced in the beam by weight of a vehicle does not exceed permissible stress.

- Deflexion of the beam under the weight of a motorcycle is too small to be registered by a fibre optic sensor.

Table 2. Results of modelling FEM.

\begin{tabular}{|c|c|c|c|}
\hline Point & $\begin{array}{l}\text { Stresses in the } \\
\text { direction of the } \\
\text { beam axis }\left[\mathrm{N} / \mathrm{mm}^{2}\right]\end{array}$ & $\begin{array}{l}\text { Deflexion of } \\
\text { the beam } \\
{[\mathrm{mm}]}\end{array}$ & $\begin{array}{l}\text { Deforma- } \\
\text { tion } \\
{[\mathrm{xE}-5]}\end{array}$ \\
\hline \multicolumn{4}{|c|}{ Case 1a } \\
\hline P1 & 1.31 & 0.135 & 0.62 \\
\hline P2 & 1.09 & 0.131 & 0.52 \\
\hline $\mathrm{P} 3$ & 0.95 & 0.121 & 0.45 \\
\hline \multicolumn{4}{|c|}{ Case 1b } \\
\hline P1 & 5.70 & 0.51 & 2.69 \\
\hline P2 & 6.29 & 0.52 & 2.95 \\
\hline $\mathrm{P} 3$ & 5.70 & 0.51 & 2.69 \\
\hline \multicolumn{4}{|c|}{ Case 2a } \\
\hline P1 & 126.26 & 13.77 & 59.82 \\
\hline $\mathrm{P} 2$ & 136.50 & 14.34 & 65.00 \\
\hline P3 & 147.24 & 14.08 & 70.09 \\
\hline \multicolumn{4}{|c|}{ Case $2 \mathrm{~b}$} \\
\hline P1 & 136.49 & 14.50 & 64.70 \\
\hline $\mathrm{P} 2$ & 136.50 & 14.94 & 64.70 \\
\hline P3 & 136.49 & 14.55 & 64.70 \\
\hline
\end{tabular}

Due to the fact that the beam was characterised by excessive stiffness which made it impossible to identify a single-track vehicle, the shape of the beam was optimised. Optimisation involved introduction of local changes in the cross-section of the existing beam. Longitudinal holes, $100 \mathrm{~mm}$ wide and $250 \mathrm{~mm}$ long, were made in the lower plane of the beam (Fig. 3).

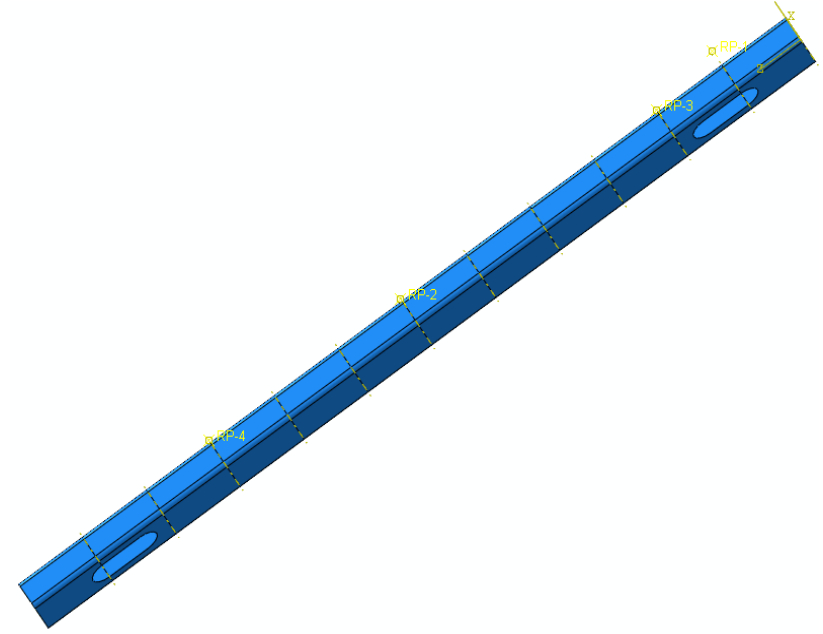

Fig. 3. Beam after the process of geometric optimisation. 
Table 3. Results of modelling FEM, beam with holes.

\begin{tabular}{|c|c|c|c|}
\hline Point & $\begin{array}{c}\text { Stresses in the } \\
\text { direction of } \\
\text { the beam axis } \\
{\left[\mathrm{N} / \mathrm{mm}^{2}\right]}\end{array}$ & $\begin{array}{l}\text { Deflexion of } \\
\text { the beam } \\
{[\mathrm{mm}]}\end{array}$ & $\begin{array}{l}\text { Deforma } \\
\text {-tion } \\
\text { [xE-5] }\end{array}$ \\
\hline \multicolumn{4}{|c|}{ Case 1a } \\
\hline A1 & 3.90 & 0.079 & 1.83 \\
\hline P1 & 1.31 & 0.140 & 0.62 \\
\hline P2 $=$ A2 & 1.09 & 0.135 & 0.52 \\
\hline P3 & 0.95 & 0.125 & 0.45 \\
\hline A3 & 0.62 & 0.047 & 0.29 \\
\hline \multicolumn{5}{|c|}{ Case 1b } \\
\hline A1 & 3.66 & 0.204 & 1.72 \\
\hline P1 & 5.70 & 0.52 & 2.70 \\
\hline P2 A2 & 6.29 & 0.53 & 2.95 \\
\hline P3 & 5.70 & 0.52 & 2.70 \\
\hline A3 & 3.70 & 0.209 & 1.74 \\
\hline \multicolumn{5}{|c|}{ Case $2 \mathrm{a}$} \\
\hline A1 & 161.35 & 6.13 & 75.30 \\
\hline P1 & 125.63 & 9.92 & 59.82 \\
\hline P2 A2 & 136.50 & 14.68 & 64.67 \\
\hline P3 & 147.24 & 14.11 & 70.09 \\
\hline A3 & 183.68 & 6.41 & 86.31 \\
\hline \multicolumn{5}{|c|}{ Case $2 \mathrm{~b}$} \\
\hline A1 & 187.46 & 6.30 & 87.53 \\
\hline P1 & 136.49 & 14.83 & 65.00 \\
\hline P2 A2 & 136.49 & 15.27 & 65.00 \\
\hline P3 & 136.49 & 14.88 & 65.00 \\
\hline A3 & 186.90 & 6.53 & 87.26 \\
\hline
\end{tabular}

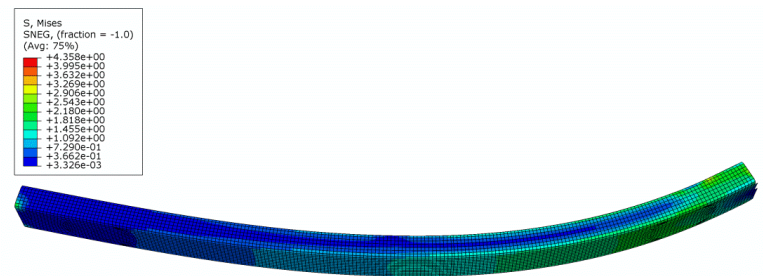

Fig. 4. Reduced stresses, case 1a, beam before the process of geometric optimisation.

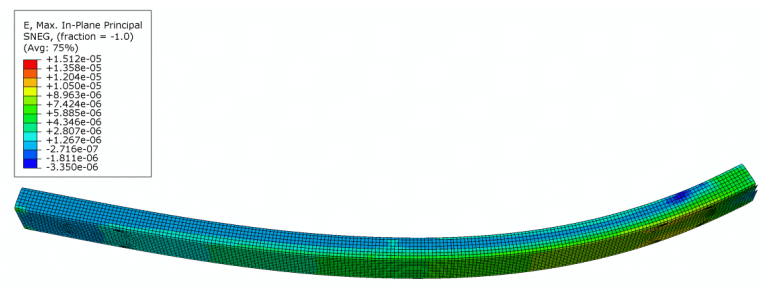

Fig. 5. Deformation, case 1a, beam before the process of geometric optimisation.

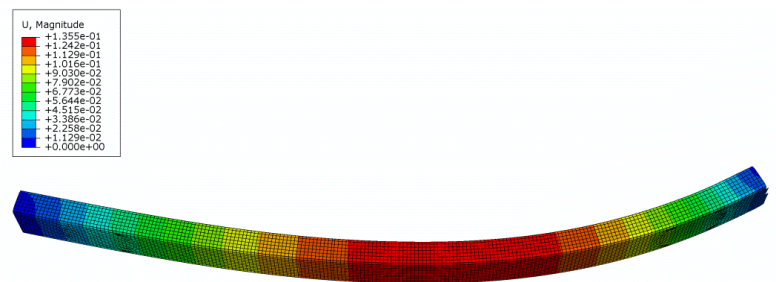

Fig. 6. Deflexion, case 1a, beam before the process of geometric optimisation.

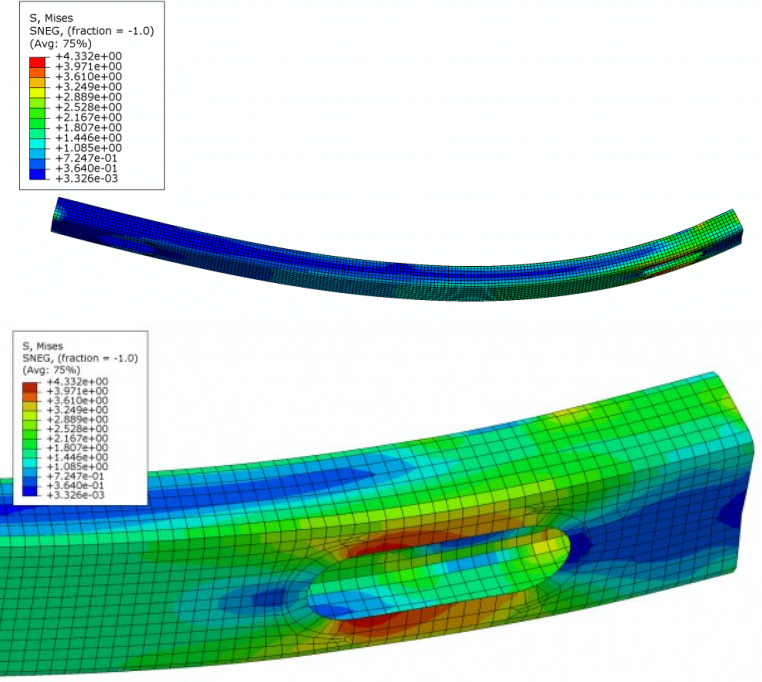

Fig. 7. Reduced stresses, case 1a, beam after the process of geometric optimisation.

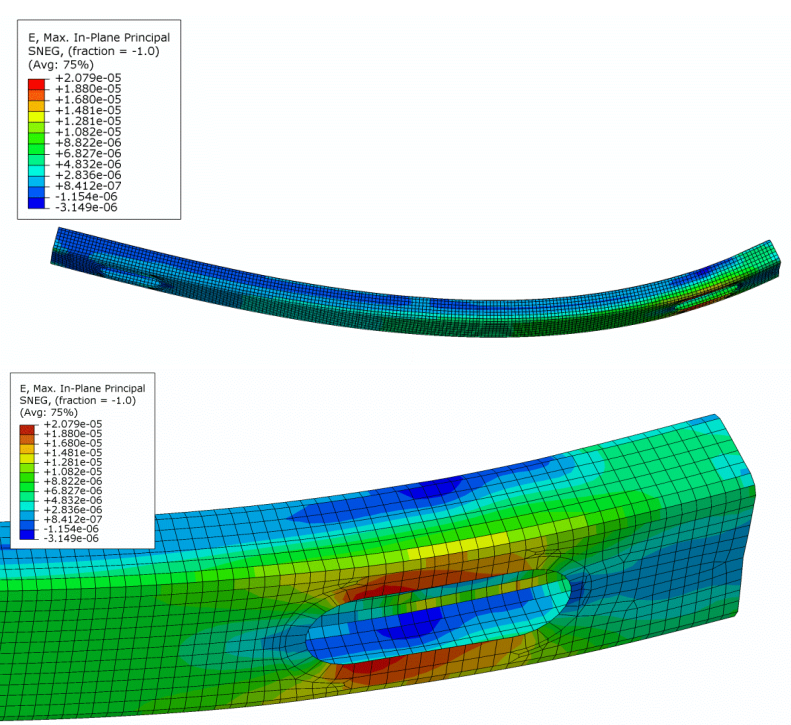

Fig. 8. Deformation, case 1a, beam after the process of geometric optimisation.
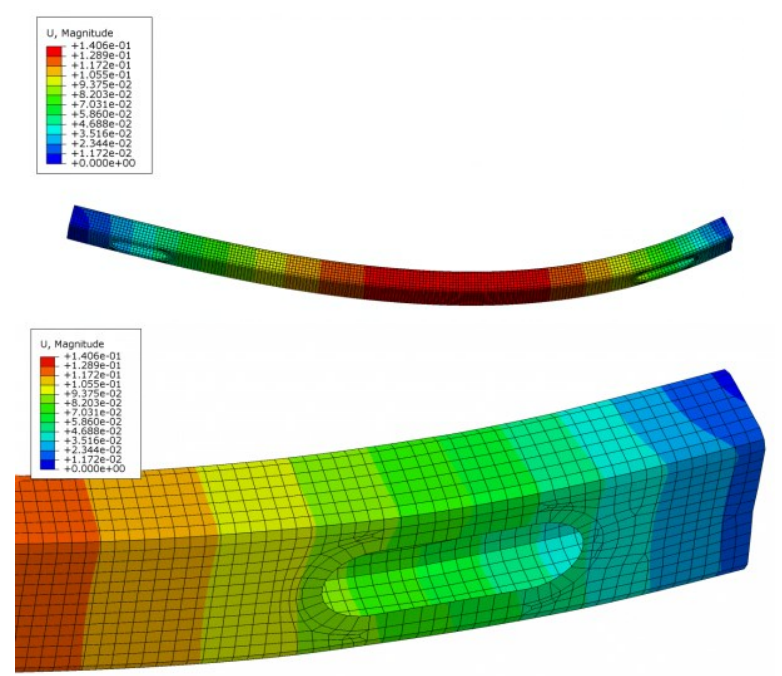

Fig. 9. Deflexion, case 1a, beam after the process of geometric optimisation. 


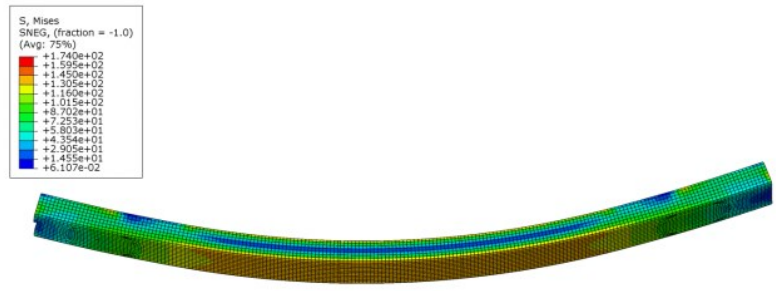

Fig. 10. Reduced stresses, case $2 b$, beam after the process of geometric optimisation.

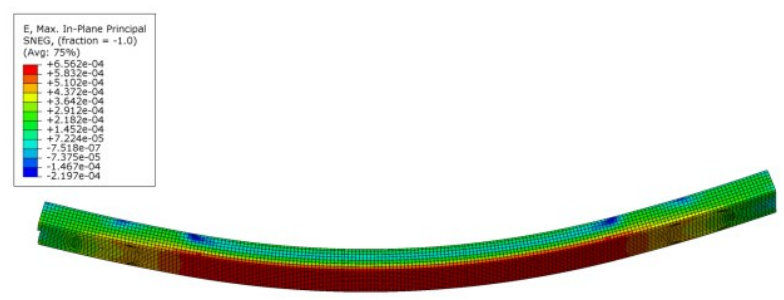

Fig. 11. Deformation, case $2 b$, beam after the process of geometric optimisation.

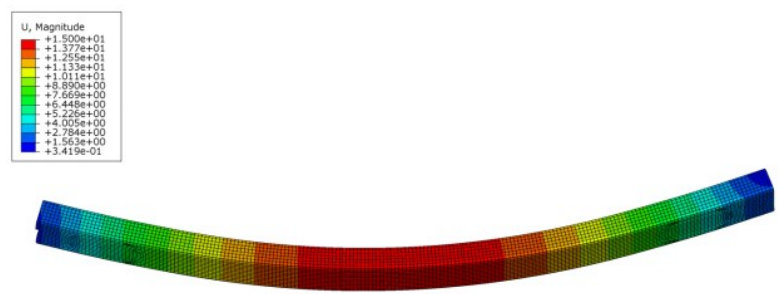

Fig. 12. Deflexion, case 2b, beam after the process of geometric optimisation.

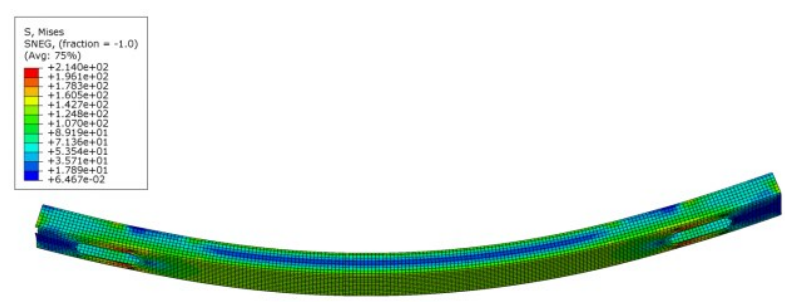

Fig. 13. Reduced stresses, case $2 b$, beam after the process of geometric optimisation.

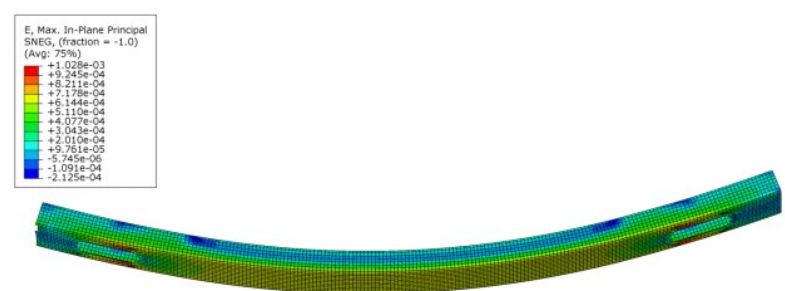

Fig. 14. Deformation, case $2 b$, beam after the process of geometric optimisation.
Two sensors were glued inside the beam along the longitudinal edge of the hole at a distance of $384 \mathrm{~mm}$ from the end of the beam, $20 \mathrm{~mm}$ from the edge of the hole - points A1 and A3. A third sensor was attached to the beam at its mid-length - point A2 (equivalent to point 2 ). Table 3 show the results of FEM strength analysis. The results of modelling are presented in Figures $7-14$.

\section{Conclusions}

Parametric models describing the influence of vehicle tyre force on the detector beam of a WIM system were developed and verified. These models were used to optimise the shape of the beam so that it could be used to measure the weight of vehicles within the permissible total weight from $250 \mathrm{~kg}$ to $10000 \mathrm{~kg}$ and to detect certain road traffic parameters. The fibre optic sensors were located on the beam so that they could register beam deformations produced by the weight of a single-track vehicle. The selected shape of the holes reducing the stiffness of the beam did not lead to exceeding of the permissible stresses in any cross-section of the beam.

\section{References}

1. B. Jacob, Weigh-in Motion of Road Vehicle. Final Report of COST 323 action, ver. 3.0 (1999)

2. D.J. Cole, D. Cebon, 6th International Conference on Road Traffic Monitoring and Control. IEE, London, 123-127 (1992)

3. N. Hoose, J. Kunz, 1998. Proceedings of 2nd European Conference Weigh in Motion of Road Vehicle, Lisbon, 461-466 (1998)

4. P. Burnos et al. Metrology and Measurement Systems. 14, 4, 507-516 (2007)

5. J. Gajda, P. Burnos, Proceedings of XV Symposium Modelling and Simulation of Measurement Systems. 199 - 204 (2005)

6. J. Gajda et al., Metrology and Measurement Systems. 14, 4, 517-527 (2007)

7. D. Stanczyk, Proceedings of the Final Symposium of the Project WAVE, Paris, 307 - 316 (1999)

8. M. Huhtala, Proceedings of the Final Symposium of the Project WAVE, Paris, 55 - 68 (1999)

9. M. Mangeas, S. Glaser, V. Dolcemascolo, Proceedings of Eurofusion, 9, 7943 - 795 (2000)

10. D. Cebon, D., C. Winkler, Transportation Research Record, TRB, 1311, 70 -78 (1991) 